\title{
A Peripheral, Intracerebral, or Intrathecal Administration of an Opioid Receptor Antagonist Blocks Illness-Induced Hyperalgesia in the Rat
}

\author{
Gavan P. McNally, Ian N. Johnston, and R. Frederick Westbrook \\ University of New South Wales
}

\begin{abstract}
We used the tail-flick response of rats to study the role of opioid receptors in illness-induced hyperalgesia. An intraperitoneal injection of lithium chloride $(\mathrm{LiCl})$ produced hyperalgesia that was blocked in a dose-dependent manner by subcutaneous injection of the opioid antagonist naloxone. Neither hyperalgesia nor its blockade by naloxone were due to variations in tail-skin temperature induced by $\mathrm{LiCl}$. Hyperalgesia was also blocked when opioid receptor antagonism was restricted to (a) the periphery, by intraperitoneal administration of the quaternary opioid receptor antagonist naloxone methiodide; (b) the brain, by intracerebroventricular microinjection of naloxone; or (c) the spinal cord, by intrathecal microinjection of naloxone. These results document a pain facilitatory role of opioid receptors in both the peripheral and central nervous systems and are discussed with reference to their analgesic and motivational functions.
\end{abstract}

Illness-inducing substances such as lithium chloride $(\mathrm{LiCl})$ or the bacterial endotoxin lipopolysaccharide (LPS) increase basal levels of nociceptive sensitivity in rats (e.g., Maier, Wiertelak, \& Watkins, 1992; Wiertelak, Smith, et al., 1994). This hyperalgesia is initiated by cytokines released from activated macrophages and involves the vagus nerve because it is abolished by sectioning of the subdiaphragmatic branch of the vagus, destruction of hepatic macrophages, or intraperitoneal administration of an interleukin-1 $\beta$ receptor antagonist (Maier, Wiertelak, Martin, \& Watkins, 1993; Watkins, Wiertelak, Goehler, et al., 1994). Illnessinduced hyperalgesia is also abolished by decerebration (Watkins, Wiertelak, Goehler, et al., 1994), but the precise forebrain mechanisms for this hyperalgesia remain unclear. Nonetheless, lesion and infusion studies have identified a critical role for vagal terminations in the nucleus of the solitary tract and the eventual activation of a pathway that descends from the nucleus raphe magnus in the rostral ventromedial medulla to the spinal cord dorsal horn, recruiting excitatory amino-acid (especially $N$-methyl-D-aspartate [NMDA]) and cholecystokinin systems (Watkins, Wiertelak, Furness, \& Maier, 1994; Wiertelak, Furness, Watkins, \& Maier, 1994; Wiertelak, Roemer, Maier, \& Watkins, 1997).

The hyperalgesia induced by $\mathrm{LiCl}$ or LPS co-occurs with other sickness behaviors that include adipsia, aphagia, hyperthermia, and reductions in locomotor and social activity (for reviews, see Hart, 1988; Kent, Bluthe, Kelley, \& Dantzer, 1992; Maier \& Watkins, 1998). This co-occurrence has been taken as evidence of a sickness (e.g., Hart, 1988; Kent et al., 1992) or recuperative (Bolles \& Fanselow, 1980) motivational system that has evolved to afford

Gavan P. McNally, Ian N. Johnston, and R. Frederick Westbrook, School of Psychology, University of New South Wales, Sydney, Australia.

This research was supported by a grant from the Australian Research Council, by Government Employee's Medical Research Fund Grant GEMRF 98/06, and by Australian Postgraduate Awards.

Correspondence concerning this article should be addressed to Gavan P. McNally, School of Psychology, University of New South Wales, Sydney, 2052, Australia. Electronic mail may be sent to g.mcnally@unsw. edu.au. protection from pathogens. In particular, it has been suggested that the recuperative function served by pain-related behaviors may be enhanced by the sickness subsequent to activation of the immune system, and that evolution has selected for mechanisms that facilitate pain during this state (Maier \& Watkins, 1998). The endogenous opioid system is an important component of this immunemediated recuperative or sickness-motivational system. For instance, injections of $\mu$-opioid receptor agonists induce a set of behaviors, including somnolence, nausea, and impaired contextual learning (e.g., Bechara \& Van der Kooy, 1985; Reisine \& Pasternak, 1995; Westbrook, Good, \& Kiernan, 1997), that are similar to those produced by injections of $\mathrm{LiCl}$ or LPS (e.g., Kent et al., 1992; Pugh et al., 1998), whereas injections of opioid receptor antagonists reduce the aversive motivational impact of LPS and LiCl (Lieblich \& Yirimiya, 1987; Shippenberg, Millan, Mucha, \& Herz, 1988).

Opioid peptides and their receptors have been identified in the immune system, and these serve a potent modulatory function (Madden, Whaley, \& Ketelsen, 1998; Peterson, Molitor, \& Chao, 1998; Sharp, Roy, \& Bidlack, 1998). These opioid-immune interactions are not restricted to the periphery because central opioid receptors also serve an important immunomodulatory role (e.g., Mellon \& Bayer, 1998) and because stimulation of the immune system increases the activity of opioid-containing cells in the central nervous system (e.g., Day, Curran, Watson, \& Akil, 1999; Ruzicka, Thompson, Watson, \& Akil, 1996). Opioid receptors also contribute to the pain modulatory consequences of illness. Thus, systemic injection of naloxone reduced the pain modulation observed when rats were tested in either the hot-plate test following injection of LPS (Yirimiya, Rosen, Donchin, \& Ovadia, 1994) or the formalin test following exposure to an $\mathrm{LiCl}$-associated context (McNally, Gorrisen, Low, \& Westbrook, 1999).

In this research, we studied whether the hyperalgesia produced by an intraperitoneal injection of $\mathrm{LiCl}$ also involves activation of opioid receptors. In the initial experiments, we examined whether an injection of the competitive opioid receptor antagonist naloxone modulates the expression of the hyperalgesia induced by $\mathrm{LiCl}$ (Experiment 1A), the dose-response properties of such modulation 
(Experiment 1B), and the role of thermoregulatory changes in the production of hyperalgesia (Experiment $1 \mathrm{C}$ ). In subsequent experiments, we studied the anatomical locus for opioid receptor involvement in hyperalgesia by restricting the actions of naloxone to the periphery (Experiment $2 \mathrm{~A}$ ), brain (Experiment $2 \mathrm{~B}$ ), and spinal cord (Experiment 2C).

\section{EXPERIMENTS 1A, 1B, AND 1C}

In Experiments 1 A-1C, we studied the effects of a subcutaneous injection of naloxone on the hyperalgesia produced by an intraperitoneal injection of $\mathrm{LiCl}$. Experiment $1 \mathrm{~A}$ used a $2 \times 2$ factorial design in which the first factor was pretreatment with either subcutaneous naloxone $(2.5 \mathrm{mg} / \mathrm{kg})$ or saline and the second factor was intraperitoneal injection with either $\mathrm{LiCl}(127.2 \mathrm{mg} / \mathrm{kg})$ or saline. Experiment IB examined the dose-response properties of naloxone's antagonism of $\mathrm{LiCl}$-induced hyperalgesia. Specifically, in this single-factor design, rats were pretreated with one of several doses of naloxone $(0,0.005,0.050,0.500$, or $5.000 \mathrm{mg} / \mathrm{kg})$ and 10 min later with $\mathrm{LiCl}$. The interpretation of data from the tail-flick test with reference to the actions of pain modulatory circuits can be confounded by an influence of tail-skin temperature on tail-flick latencies (Berge, Garcia-Cabrera, \& Hole, 1988; Hole \& Tjolsen, 1993). Thus, any effect of an injection of $\mathrm{LiCl}$ or naloxone detected in Experiments $1 \mathrm{~A}$ and $1 \mathrm{~B}$ could be secondary to druginduced shifts in peripheral blood flow affecting heat transfer in the tail. We examined this possibility using two approaches. First, in Experiments $1 \mathrm{~A}$ and $1 \mathrm{~B}$ we measured tail-skin temperatures of rats immediately before the tail-flick test. Second, in Experiment $1 \mathrm{C}$ we examined whether rats exhibited hyperalgesia when their tail-skin temperatures had been increased by immersion in water and whether any such hyperalgesia was reversed by $2.5 \mathrm{mg} / \mathrm{kg}$ naloxone. The design of this experiment consisted of the $2 \times 2$ factorial described for Experiment $1 \mathrm{~A}$.

\section{Method}

\section{Subjects}

The subjects were experimentally naive male Wistar rats weighing between 300 and $400 \mathrm{~g}$. They were obtained from the colony of SpecificPathogen-Free rats maintained by the Combined Universities Laboratory Animal Services (Sydney, Australia). There were 32 rats in Experiment 1A, 40 rats in Experiment 1B, and 32 rats in Experiment 1C. Rats were housed in plastic boxes ( $65 \mathrm{~cm}$ long $\times 40 \mathrm{~cm}$ wide $\times 22 \mathrm{~cm}$ high) with 6 to 8 rats per box. The wire mesh roof of each box held food and water bottles that were continuously available. The boxes were kept in a colony room maintained under natural lighting. The experiments were conducted between 9 a.m. and 5 p.m.

\section{Apparatus}

The tail-flick apparatus consisted of a waterbath whose temperature could be controlled $\pm 0.5^{\circ} \mathrm{C}$ by a Ratek Open-Bath Thermoregulator (Ratek Instruments, Melbourne, Australia). The temperature of this waterbath was maintained at $51^{\circ} \mathrm{C}$ for tail-flick testing. A second waterbath whose temperature was maintained at $34^{\circ} \mathrm{C}$ was used to preheat the tail in Experiment $1 \mathrm{C}$. Tail-skin temperature was measured with a digital thermal probe (Anritsu, Tokyo, Japan). The waterbaths were located in a laboratory whose ambient temperature was maintained between 21 and $23{ }^{\circ} \mathrm{C}$. The laboratory also contained plastic buckets ( $26 \mathrm{~cm}$ diameter $\times 45 \mathrm{~cm}$ height) with air holes drilled in the lid and sides. These buckets served as chambers in which rats were kept in isolation from each other when they were brought to the laboratory.

\section{Drugs}

$\mathrm{LiCl}$ anhydrous (Becton Dickinson, Sydney, Australia) was dissolved in distilled water to obtain a concentration of $6.36 \mathrm{~g} / 1(0.15 \mathrm{M})$ and was injected intraperitoneally in a volume of $20 \mathrm{ml} / \mathrm{kg}$, producing a dose of $127.2 \mathrm{mg} / \mathrm{kg}$. Naloxone hydrochloride (Sigma Chemical Company, St. Louis, MO) was dissolved in sterile, nonpyrogenic saline $(0.9 \%$ [ $\mathrm{w} / \mathrm{vol}])$.

\section{Procedure}

During the 5 days before the start of the experiment, each rat was handled for 1 min each day.

\section{Familiarization}

Across Days 1-4 of the experiments, rats were transported to the laboratory. On arrival, rats were placed in the plastic buckets for $20 \mathrm{~min}$, removed, handled, and returned to the buckets. We repeated this handling three more times at 5-min intervals to familiarize the rats with the procedures to be used on the tests.

\section{Test}

Experiment $1 A$. On Day 5, rats were transported to the laboratory and placed in the plastic buckets for $20 \mathrm{~min}$. We then determined baseline tail-skin temperatures and tail-flick latencies by taking the average of the last three of the four trials spaced 5 min apart. Tail-skin temperatures were measured immediately before the tail-flick test. For tail-skin temperature testing, the thermal probe was placed on the dorsal surface of the tail, $8 \mathrm{~cm}$ from the distal tip. For tail-flick testing, the distal $4-\mathrm{cm}$ portion of the tail was immersed in the waterbath, and latency to completely remove the tail was recorded with a stopwatch. Immediately following tail flick, we wiped the tail with a flannel cloth to prevent hot water clinging to the tail. Five minutes after baseline determination, rats were injected subcutaneously with either naloxone or saline. Ten minutes later, rats were injected intraperitoneally with either $\mathrm{LiCl}$ or saline. Tail-flick and tail-skin temperature testing commenced $5 \mathrm{~min}$ later and were repeated once every $10 \mathrm{~min}$ for 40 min. The tail-flick response is predominanlly organized at the level of the spinal cord. However, there is evidence that response latencies greater than 2 s require a degree of supraspinal integration (Jensen \& Yaksh, 1986). Thus, it is worth noting that in the present experiments, tail-flick latencies represent more than spinal reflexive nociceptive processing.

Experiment $1 B$. On Day 5, rats were transported to the laboratory and placed in the plastic buckets. The procedure for baseline tail-flick latency and tail-skin temperature determination was the same as that described for Experiment 1A. Five minutes after baseline tail-flick latency and tail-skin temperature determination, rats were injected subcutaneously with either 0 , $0.005,0.050,0.500$, or $5.000 \mathrm{mg} / \mathrm{kg}$ naloxone. Ten minutes later, rats were injected intraperitoneally with $\mathrm{LiCl}$. Tail-flick and tail-skin temperature testing commenced $5 \mathrm{~min}$ later and were repeated once every $10 \mathrm{~min}$ for $40 \mathrm{~min}$.

Experiment $1 C$. On Day 5, rats were transported to the laboratory and placed in the plastic buckets. The procedure for baseline tail-flick and tail-skin determination was the same as that described previously except that tails were preheated by immersion in the $34-^{\circ} \mathrm{C}$ waterbath for $15 \mathrm{~s}$ immediately before the test. Five minutes after baseline tail-flick latency and tail-skin temperature determination, rats were injected subcutaneously with either naloxone or saline. Ten minutes later, rats were injected intraperitoneally with either $\mathrm{LiCl}$ or saline. Tail-flick and tail-skin temperature testing commenced $5 \mathrm{~min}$ later and were repeated once every $10 \mathrm{~min}$ for $40 \mathrm{~min}$. The tail was immersed in the $34-^{\circ} \mathrm{C}$ waterbath for $15 \mathrm{~s}$ immediately prior to each testing occasion, and tail-skin temperature measured. 


\section{Statistical Analyses}

Pilot studies indicated that the effects of an injection of $\mathrm{LiCl}$ and naloxone on tail-flick latency as well as tail-skin temperature were stable across the 30-40-min test period used in these experiments. Therefore, the average of performances across these trials was used as the basis for analysis. The data in these and subsequent experiments were analyzed by means of planned orthogonal contrasts written to partition the variance attributable to the between-groups manipulation into standard components (i.e., main effect of pretreatment and main effect of injection of $\mathrm{LiCl}$ or saline as well as their interaction). The per-contrast error rate was controlled at the 0.05 level with the procedure described by Hays (1972; see Harris, 1994, for review).

\section{Results and Discussion}

The top left-hand panel of Figure 1 shows the mean $(+S E M)$ tail-flick latencies for rats in each of the groups in Experiment 1A. There were no significant differences between groups in baseline tail-flick latencies $(F \mathrm{~s}<1)$. The mean baseline latencies were $5.8 \mathrm{~s}$ for rats injected twice with saline (saline-saline group), $5.9 \mathrm{~s}$ for those injected with saline before $\mathrm{LiCl}$ (saline$\mathrm{LiCl}$ group), $6.1 \mathrm{~s}$ for those injected with naloxone then with saline (naloxone-saline group), and $5.7 \mathrm{~s}$ for rats injected with naloxone then with $\mathrm{LiCl}$ (naloxone-LiCl group). Inspection of the panel indicates that rats injected with $\mathrm{LiCl}$ exhibited a substantial hy-

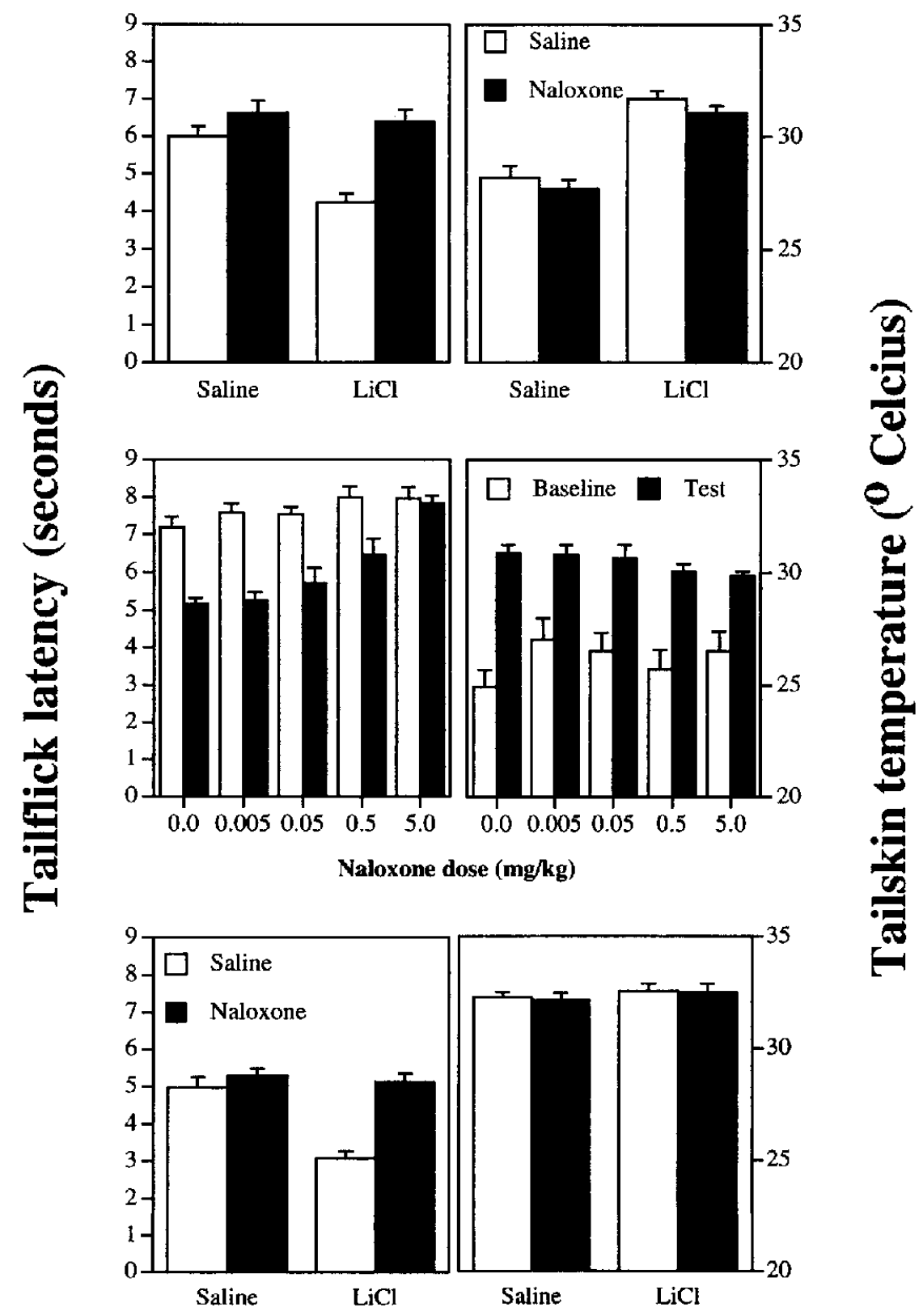

Figure 1. Mean ( $+S E M$ ) tail-flick latencies (left) and tail-skin temperatures (right) from Experiment 1A (top), Experiment $1 \mathrm{~B}$ (middle), and Experiment $\mathrm{C}$ (bottom). $\mathrm{LiCl}=$ lithium chloride. 
peralgesia that appeared to have been reversed by pretreatment with naloxone. These observations were confirmed by the statistical analysis.

There was a significant main effect for injection of $\mathrm{LiCl}$ versus saline, $F(1,28)=21.9$, critical $F(1,28)=4.2$. There was also a significant main effect for injection of naloxone versus saline, $F(1$, $28)=40.9$. Finally, the $2 \times 2$ interaction was also significant, $F(1$, $28)=12.5$, such that the effects of pretreatment with naloxone were greater among rats later injected with $\mathrm{LiCl}$ than those later injected with saline.

The top right-hand panel of Figure 1 shows the mean $(+S E M)$ tail-skin temperatures for rats in Experiment 1A. There were no differences between groups in baseline tail-skin temperatures, $F$ s $<1$ : means $=23.3{ }^{\circ} \mathrm{C}$, saline-saline group; $23.6{ }^{\circ} \mathrm{C}$, saline$\mathrm{LiCl}$ group; $22.9^{\circ} \mathrm{C}$, naloxone-saline; $23.0^{\circ} \mathrm{C}$, naloxone- $\mathrm{LiCl}$ group. Inspection of the panel indicates that $\mathrm{LiCl}$ increased tailskin temperatures compared with those of rats injected with saline and that this increase in tail-skin temperatures among LiCl-treated rats was comparable among rats pretreated with saline or with naloxone. These observations were confirmed by the statistical analysis. There was a significant main effect for injection of $\mathrm{LiCl}$ versus saline, $F(1,28)=74.4$, critical $F(1,28)=4.2$. However, there was no main effect for injection of naloxone versus saline, $F$ $=2.5$. Finally, there was no significant $2 \times 2$ interaction, $F<1$.

The middle left-hand panel of Figure 1 shows the mean (+ $S E M$ ) baseline and test tail-flick latencies for rats in Experiment 1B. There were no differences between groups in baseline tail-flick latencies $(F \mathrm{~s}<2.6)$. Inspection of the panel indicates that pretreatment with naloxone produced a dose-dependent reduction in the hyperalgesia elicited by $\mathrm{LiCl}$. There was no difference in tail-flick latencies between rats pretreated with either 0.005 or $0.050 \mathrm{mg} / \mathrm{kg}$ naloxone and control rats injected with $0 \mathrm{mg} / \mathrm{kg}$ naloxone. However, hyperalgesia was partially attenuated by a subcutaneous injection of $0.500 \mathrm{mg} / \mathrm{kg}$ naloxone and completely prevented by an injection of $5.000 \mathrm{mg} / \mathrm{kg}$ naloxone. These observations were confirmed by the statistical analysis. There was a significant difference in tail-flick latencies between rats pretreated with $5.000 \mathrm{mg} / \mathrm{kg}$ naloxone versus rats pretreated with $0.500,0.050,0.005$, and $0 \mathrm{mg} / \mathrm{kg}$ naloxone, $F(1,35)=47.5$; critical $F(1,35)=4.1$. There was also a significant difference in tail-flick latencies between rats pretreated with $0.500 \mathrm{mg} / \mathrm{kg}$ naloxone versus rats pretreated with $0.050,0.005$, and $0 \mathrm{mg} / \mathrm{kg}, F(1$, $35)=10.51$. However, there was no significant difference in tail-flick latencies between rats pretreated with $0.050 \mathrm{mg} / \mathrm{kg}$ naloxone versus rats pretreated with 0.005 or $0 \mathrm{mg} / \mathrm{kg}, F=2.0$, nor was there a significant difference between rats in these latter two groups, $F<1$.

The middle right-hand panel of Figure 1 shows the mean $(+$ $S E M$ ) baseline and test tail-skin temperatures for rats in Experiment $1 B$. There were no differences between groups in baseline tail-skin temperatures latencies ( $F \mathrm{~S}<3.5$ ). Inspection of the panel indicates that none of the doses of naloxone exerted any detectable effect on tail-skin temperatures. This observation was confirmed by the statistical analysis. There was no significant difference in tail-skin temperatures between rats injected with $5.000 \mathrm{mg} / \mathrm{kg}$ naloxone and those in the remaining groups, $F=2.8$; between rats injected with $0.500 \mathrm{mg} / \mathrm{kg}$ and those injected with lower doses, $F=2.7$; nor between rats injected with $0.050 \mathrm{mg} / \mathrm{kg}$ versus rats injected with 0.005 or $0 \mathrm{mg} / \mathrm{kg}, F<1$; nor between these latter two groups, $F<1$, critical $F(1,35)=4.1$.
The bottom left-hand panel of Figure 1 shows the mean (+ $S E M$ ) tail-flick latencies of rats in Experiment $1 \mathrm{C}$. There were no differences between groups in baseline tail-flick latencies, $F_{\mathrm{S}}<1$ : means $=5.3 \mathrm{~s}$, saline-saline group; $5.3 \mathrm{~s}$, saline-LiCl group; $5.6 \mathrm{~s}$, naloxone-saline group; $5.4 \mathrm{~s}$, naloxone- $\mathrm{LiCl}$ group. Inspection of the panel suggests that $\mathrm{LiCl}$ produced hyperalgesia that was prevented by pretreatment with naloxone. The statistical analysis revealed a significant main effect for injection of $\mathrm{LiCl}$ versus saline, $F(1,28)=32.1$, critical $F(1,28)=4.2$. There was also a significant main effect for injection of naloxone versus saline, $F(1$, $28)=23.9$. Importantly, there was a significant $2 \times 2$ interaction, $F(1,28)=16.7$, such that the effects of pretreatment with naloxone were greater among rats later injected with $\mathrm{LiCl}$ than those later injected with saline.

The bottom right-hand panel of Figure 1 shows the mean (+ $S E M$ ) tail-skin temperatures from rats in Experiment 1C. There were no differences between groups in baseline tail-skin temperatures, $F \mathrm{~s}<1$ : means $=32.0^{\circ} \mathrm{C}$, saline-saline group; $31.8^{\circ} \mathrm{C}$ saline- $\mathrm{LiCl}$ group; $32.0{ }^{\circ} \mathrm{C}$ naloxone-saline group; $31.6{ }^{\circ} \mathrm{C}$ naloxone- $\mathrm{LiCl}$ group. Inspection of baseline tail-skin temperatures indicates that the experimental manipulation of tail-skin temperatures was successful: Baseline tail-skin temperatures for all groups were elevated in the present experiment, and there was no differential effect of $\mathrm{LiCl}$ versus saline on tail-skin temperatures. This observation was confirmed by the statistical analysis. There was no significant main effect for injection of $\mathrm{LiCl}$ versus saline, $F<1$. There was also no significant main effect for injection of naloxone versus saline, $F<1$. Finally, there was no significant $2 \times 2$ interaction, $F<1$.

\section{EXPERIMENTS 2A, 2B, AND 2C}

Experiments $1 \mathrm{~A}-\mathrm{lC}$ provided evidence for a hyperalgesic effect of an intraperitoneal injection of $\mathrm{LiCl}$ that is mediated, at least in part, by activity at opioid receptors. The present experiments studied the anatomical locus for opioid receptor involvement in $\mathrm{LiCl}$-induced hyperalgesia. In Experiment $2 \mathrm{~A}$ we pretreated rats with a quaternary form of naloxone, which does not readily cross the blood-brain barrier, to restrict opioid receptor antagonism to the periphery (Experiment 2A; see also Russell, Bass, Goldberg, Schuster, \& Merz, 1982). In Experiment 2B we pretreated rats with an intracerebroventricular infusion of naloxone to restrict opioid receptor antagonism to supraspinal sites. In Experiment $2 \mathrm{C}$ we pretreated rats with an intrathecal infusion of naloxone to restrict opioid receptor antagonism to spinal sites. These experiments employed the same $2 \times 2$ factorial design described for Experiment $1 \mathrm{~A}$ in which the first factor was whether rats were pretreated with naloxone or saline and the second factor was whether they were then injected with $\mathrm{LiCl}$ or saline.

\section{Method}

\section{Subjects, Apparatus, and Drugs}

The subjects were experimentally naive adult male Wistar rats obtained from the same source and maintained under the same conditions as described for Experiments 1A, 1B, and 1C. There were 32 rats in Experiment 2A, 24 rats in Experiment $2 \mathrm{~B}$, and 27 rats in Experiment $2 \mathrm{C}$ (after surgery and histology). After surgery in Experiments $2 \mathrm{~B}$ and $2 \mathrm{C}$, rats were housed singly in rack-mounted wire cages. Food and water were continuously available in these cages. All apparatus was the same as that described 
previously. We dissolved naloxone methiodide (Research Biochemical International, Natick, MA) in sterile, isotonic saline to obtain a concentration of $4 \mathrm{mg} / \mathrm{ml}$ for Experiment $2 \mathrm{~A}$. Naloxone hydrochloride was dissolved in sterile, nonpyrogenic saline $(0.9 \%$ [wt/vol]) to obtain a concentration of $5 \mu \mathrm{g}$ per $3 \mu \mathrm{l}$ for Experiments $2 \mathrm{~B}$ and $2 \mathrm{C}$.

\section{Surgery and Infusion}

Rats were handled for 5 days before surgery and injected with a prophylactic dose of $0.1 \mathrm{ml}$ of a $300.0 \mathrm{mg} / \mathrm{ml}$ solution of procaine penicillin on the day of surgery. Rats were anesthetized using intraperitoneal injections of $1.3 \mathrm{ml} / \mathrm{kg}$ of the anesthetic ketamine at a concentration of 100.0 $\mathrm{mg} / \mathrm{ml}$ and $0.3 \mathrm{ml} / \mathrm{kg}$ of the muscle relaxant xylazine at a concentration of $20.0 \mathrm{mg} / \mathrm{ml}$. Briefly, a 22-gauge guide cannula (Plastics One, Roanoke, VA) was aimed to terminate $0.3 \mathrm{~mm}$ dorsal to the right lateral ventricle by positioning it through a hole drilled $0.8 \mathrm{~mm}$ posterior and $1.5 \mathrm{~mm}$ lateral to bregma. During drug infusion, the 26-gauge microinjection cannula projected a further $1 \mathrm{~mm}$ to terminate in the ventricle. The microinjection cannula was connected to a $25-\mu \mathrm{l}$ Hamilton glass syringe operated by an infusion pump (Harvard Apparatus, South Natick, MA). Drugs were infused across a 1-min period, and the microinjection cannula left in place for another $1 \mathrm{~min}$ to permit diffusion from the tip of the cannula. The guide cannula was fixed in position with dental cement and anchored by three jeweler's screws. A dummy cannula was kept in place at all other times except during drug infusion. At the end of the experiment, rats were given an overdose of sodium pentobarbital, and their brains removed. Unfixed brains were sectioned coronally at $40 \mu \mathrm{m}$ and stained with cresyl violet to determine the location of the cannulas. Rats whose microinjection tips were more than $0.5 \mathrm{~mm}$ outside the ventricle were excluded from the analysis (Paxinos \& Watson, 1986). Rats were allowed 5 days recovery between surgery and the start of the experiment.

Intrathecal surgery was performed as described by Storkson, Kjorsvik, and Hole (1996). Briefly, an 18-gauge needle was inserted between the L5 and $L 6$ vertebrae. The catheter $(30-\mathrm{cm}$, sterile PE-10 tubing) was inserted through the needle and advanced $3.0 \mathrm{~cm}$ rostrally beyond its tip, terminating in the lumbosacral enlargement. The 18-gauge needle was removed, and the catheter sutured to the superficial musculature of the lower back before being tunneled subcutaneously to exit through a small incision made in the dorsal neck region. The catheter was then flushed with sterile saline and heat sealed. Microinjections of drugs during testing were followed by an additional microinjection of $25 \mu \mathrm{l}$ saline to ensure the drug reached the cord. Correct intrathecal placement was confirmed at the time of surgery by tail flick or hind-paw retraction during catheter insertion and after the completion of tail-flick testing by infusion of $10 \mu \mathrm{l} 2.0 \%$ (wt/vol) lidocaine, which produced paralysis of the hindquarters. Rats were then overdosed with intraperitoneal sodium pentobarbital. Rats were allowed 5 days recovery between surgery and the start of the experiment.

\section{Procedure}

\section{Familiarization}

Across Days 1-4 of the experiments, rats were familiarized with the handling procedures and test apparatus as described for Experiments $1 \mathrm{~A}$ $1 \mathrm{~B}$, and $1 \mathrm{C}$.

\section{Test}

On Day 5 of the experiments, rats were tested. Baseline tail-flick latencies were determined in the manner described previously. Five minutes after baseline determination, rats in Experiment $2 \mathrm{~A}$ received an intraperitoneal injection of $4 \mathrm{mg} / \mathrm{kg}$ naloxone methiodide or saline, rats in Experiment $2 \mathrm{~B}$ received an intracerebroventricular microinjection of either $5 \mu \mathrm{g}$ naloxone or saline, and rats in Experiment $2 \mathrm{C}$ received an intrathecal microinjection of either $5 \mu \mathrm{g}$ naloxone or saline. Ten minutes later, rats were injected intraperitoneally with either $\mathrm{LiCl}$ or saline. Tailflick testing commenced $5 \mathrm{~min}$ later and was repeated once every $5 \mathrm{~min}$ for $30 \mathrm{~min}$.

\section{Results and Discussion}

The left panel of Figure 2 shows the mean $(+S E M)$ tail-flick latencies for rats in each of the four groups in Experiment $2 \mathrm{~A}$. There were no differences between groups in baseline tail-flick latencies, $F \mathrm{~s}<2:$ means $=5.6 \mathrm{~s}$, saline-saline group; $5.5 \mathrm{~s}$, saline-LiCl group; $5.6 \mathrm{~s}$, naloxone methiodide-saline group; $5.9 \mathrm{~s}$, naloxone methiodide- $\mathrm{LiCl}$ group. Inspection of the panel indicates that the quaternary opioid receptor antagonist naloxone methiodide had little effect on tail-flick latencies among rats later injected with saline (naloxone methiodide-saline group vs. saline-saline group) but appeared to have prevented the hyperalgesia among rats subsequently injected with $\mathrm{LiCl}$ (naloxone methiodide- $\mathrm{LiCl}$ group vs. saline-LiCl group). These observations were confirmed by the

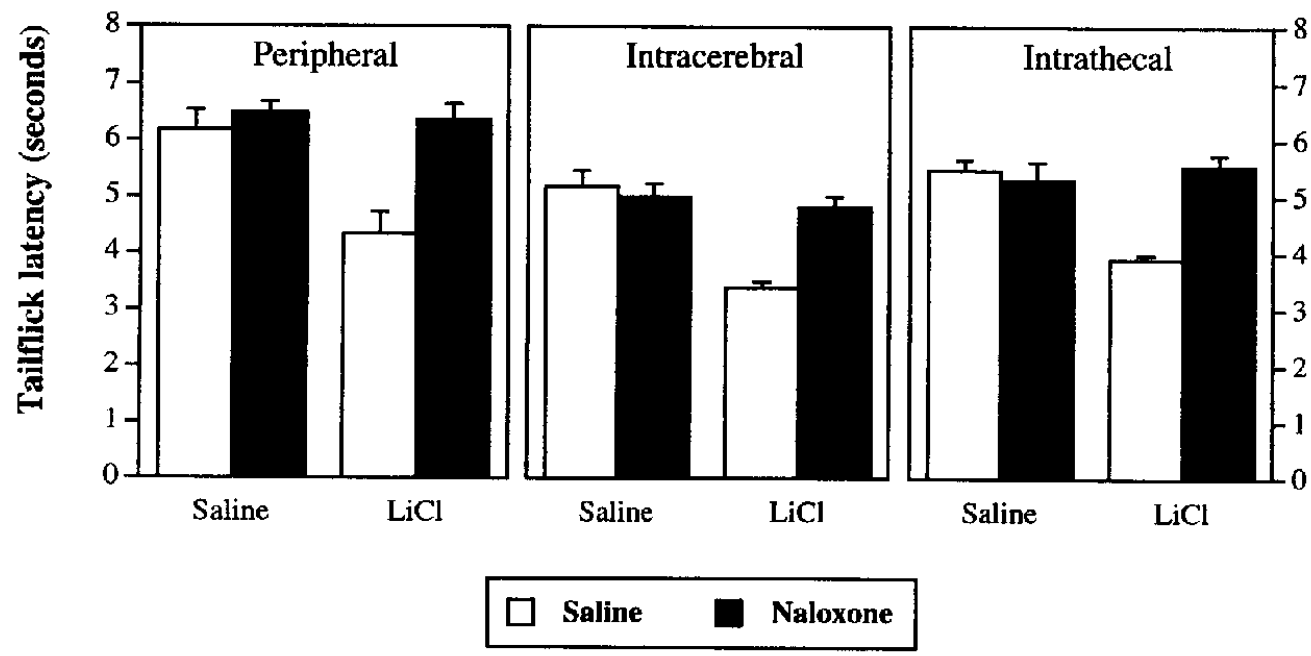

Figure 2. Mean (+ SEM) tail-flick latencies from Experiment 2A (left), Experiment 2B (middle), and Experiment $2 \mathrm{C}$ (right). $\mathrm{LiCl}=$ lithium chloride. 
statistical analysis. There was a significant main effect for injection of $\mathrm{LiCl}$ versus injection of saline, $F(1,28)=16.2$, critical $F(1$, $28)=4.2$. There was also a significant main effect for injection of naloxone methiodide versus saline, $F(1,28)=11.8$. Importantly, there was a significant $2 \times 2$ interaction, $F(1,28)=8.6$, such that the effect of naloxone methiodide was greater among rats subsequently injected with $\mathrm{LiCl}$ than with saline. Thus, these results document evidence for the involvement of peripheral opioid receptors in LiCl-induced hyperalgesia.

The middle panel of Figure 2 shows the mean $(+S E M)$ tail-flick latencies for rats in Experiment $2 \mathrm{~B}$. There were no differences between groups in baseline tail-flick latencies, $F_{\mathrm{S}}<3.9$ : means $=4.6 \mathrm{~s}$, saline-saline group; $4.3 \mathrm{~s}$, saline- $\mathrm{LiCl}$ group; $4.3 \mathrm{~s}$, naloxone-saline group; $4.4 \mathrm{~s}$, naloxone- $\mathrm{LiCl}$ group. Inspection of the panel indicates that $\mathrm{LiCl}$ produced hyperalgesia that was reversed by an intracerebroventricular microinjection of naloxone. These observations were confirmed by the statistical analysis. There was an overall significant main effect for injection of $\mathrm{LiCl}$ versus saline, $F(1,20)=19.1$, critical $F(1,20)=4.5$. There was also a significant main effect for intracerebroventricular microinjection of naloxone versus saline, $F(1,20)=8.4$. Importantly, there was also a significant $2 \times 2$ interaction, $F(1,20)=12.6$, such that the effect of naloxone was greater among rats later injected with $\mathrm{LiCl}$ than with saline. Thus, these results document evidence for the involvement of supraspinal opioid receptors in LiCl-induced hyperalgesia.

The right-hand panel of Figure 2 shows the mean ( $+S E M$ ) tail-flick latencies for rats in Experiment $2 \mathrm{C}$. There were no differences between groups in baseline tail-flick latencies, $F \mathrm{~s}<3.5$ : means $=5.2 \mathrm{~s}$, saline-saline group; $5.7 \mathrm{~s}$, saline-LiCl group; $4.9 \mathrm{~s}$, naloxone-saline group; $5.2 \mathrm{~s}$, naloxone-LiCl group. Inspection of the panel indicates that $\mathrm{LiCl}$ produced hyperalgesia that was reversed by an intrathecal microinjection of naloxone. These observations were confirmed by the statistical analysis. There was a significant main effect for injection of $\mathrm{LiCl}$ versus saline, $F(1,23)=6.4$, critical $F(1,23)=4.2$. There was no significant main effect for intrathecal microinjection of naloxone versus saline, $F(1,23)=3$.9. Importantly, there was a significant $2 \times 2$ interaction, $F(1,23)=7.6$, such that the effect of intrathecal microinjection of naloxone was greater among rats later injected intraperitoneally with $\mathrm{LiCl}$ than with saline. Thus, these results document evidence for the involvement of spinal opioid receptors in $\mathrm{LiCl}$-induced hyperalgesia.

\section{GENERAL DISCUSSION}

This series of experiments has confirmed that an intraperitoneal injection of the illness-inducing drug $\mathrm{LiCl}$ produces hyperalgesia when rats are tested for pain sensitivity with the tail-flick test. These experiments have also shown that opioid receptors contribute to illness-induced hyperalgesia because a subcutaneous injection of naloxone prevented, in a dose-dependent manner, the expression of hyperalgesia. There was evidence here that the population of opioid receptors contributing to hyperalgesia is widespread throughout the nervous system because restricting the actions of naloxone to either the peripheral (Experiment $2 \mathrm{~A}$ ) or central nervous systems (Experiments $2 \mathrm{~B}$ and $2 \mathrm{C}$ ) was equally effective in preventing the expression of hyperalgesia.

It is unlikely that the reversal of hyperalgesia by an injection of naloxone in these experiments can be attributed to drug-induced alterations in thermoregulation. Specifically, although intraperitoneal injection of $\mathrm{LiCl}$ both increased tail-skin temperature and decreased tail-flick latency, the former was insensitive to naloxone injection across a wide dose range, whereas the latter was blocked in a dose-dependent manner by the opioid antagonist. Moreover, hyperalgesia as well as its reversal by a subcutaneous injection of naloxone was obscrved when tail-skin temperatures for rats in all groups were experimentally equated by immersion in a $34-{ }^{\circ} \mathrm{C}$ waterbath immediately before the test. If either hyperalgesia or its naloxone sensitivity were secondary to drug-induced changes in tail-skin temperature, then experimentally equating all groups on tail-skin temperature should have abolished both effects. Instead, both hyperalgesia and its reversal by naloxone were preserved under these conditions. These findings are consistent with demonstrations that antinociception in the tail-flick test is also independent of alterations in thermoregulation (Lichtman, Smith, \& Mar(in, 1993).

The evidence presented here for widespread opioid receptor involvement in $\mathrm{LiCl}$-induced hyperalgesia could have been secondary to a widespread diffusion of naloxone from the site of injection in these experiments. For example, it could be argued that the effects of centrally administered naloxone were secondary to a diffusion of the drug to the periphery. However, the amount of naloxone that diffuses to the periphery within $60 \mathrm{~min}$ of intracerebral microinjection is low (a maximum of $5 \%$ of the total dose) and is significantly lower than that observed within 60 min of central administration of a quaternary form of the antagonist (a maximum of $10 \%$ of the total dose; Schroeder, Weinger, Vakassian, \& Koob, 1991). Moreover, the results of Experiment 1B directly address this possibility. If the effects of intracerebroventricular or intrathecal microinjections of naloxone were attributable to peripheral diffusion, then the same dose of naloxone administered systemically should have also prevented hyperalgesia. Instead, the results of Experiment $1 \mathrm{~B}$ showed that this dose of naloxone as well as an injection of $0.050 \mathrm{mg}$ naloxone, an order of magnitude higher than the dose of the drug administered centrally in Experiments $2 \mathrm{~B}$ and $2 \mathrm{C}$, failed to affect the expression of hyperalgesia. These results are inconsistent with an interpretation that accords a causal role to peripheral diffusion of centrally administered naloxone in the prevention of hyperalgesia. Alternatively, it could be suggested that the effects of intrathecal naloxone reported in Experiment 2C were secondary to the diffusion of the drug to supraspinal sites. However, the available data from conditions similar to those used here indicate minimal supraspinal diffusion within $25 \mathrm{~min}$ of microinjection (Storkson et al., 1996). In the absence of microinjections into discrete brain regions, it is possible that the effects of intracerebroventricular microinjection of naloxone (Experiment 2B) could be explained by the caudal spread of the drug to the spinal cord, but the effects of intracerebroventricular and intrathecal infusions of the same volume as used here have previously been dissociated (McNally \& Westbrook, 1998, Experiments 3 and 4). Moreover, even if caudal diffusion were causal to the effects of the intracerebroventricular infusion of naloxone, it does not reduce the central finding of these experiments: Opioid receptors located in the periphery as well as in the central nervous system (or at least in the spinal cord) serve a pronociceptive function following an intraperitoneal injection of LiCl.

The evidence for a hyperalgesic function of peripheral and central opioid receptors documented in the present experiments is 
consistent with previous demonstrations of a pronociceptive role for these receptors. For example, peripheral opioid receptors contribute to the hyperalgesia produced by noxious chemical stimulation (Van der Kooy, 1986), and antagonism of spinal opioid receptors prevents the hyperalgesia produced by stimulation of vagal afferents (Ren, Randich, \& Gebhart, 1991). Moreover, this evidence for the involvement of peripheral and central opioid receptors in pronociception parallels demonstrations that both peripheral-in particular those derived from the adrenal-and central opioid peptides contribute critically to particular instances of stress-induced hypoalgesia (e.g., Lewis, Tordoff, Sherman, \& Liebeskind, 1982). Nonetheless, it is difficult to reconcile this pronociceptive role with the well-documented hypoalgesic function of these receptors. In the spinal cord, opioid receptors are commonly viewed as producing hypoalgesia through two actions. The first is through the inhibition of transmitter release from presynaptic primary afferent terminals, and the second is through the inhibition of postsynaptic nociceptive neurons (for review, see McNally \& Akil, in press). There are grounds for suggesting that this postsynaptic activity could also contribute to hyperalgesia. Chen and Huang (1991) reported that binding to $\mu$-opioid receptors potentiated the consequences of activation of trigeminal dorsal horn NMDA receptors in vitro. Moreover, Martin, Nie, and Siggins (1997) identified a similar in vitro potentiation of the consequences of NMDA receptor activation by $\mu$-opioid receptors on neurons from the nucleus accumbens, which was restricted to postsynaptic sites. At the level of the spinal cord, activation of NMDA receptors has been shown to mediate the hyperalgesia produced by intraperitoneal injection of $\mathrm{LiCl}$ and other illnessinducing drugs (Watkins, Wiertelak, Furness, \& Maier, 1994). According to this line of reasoning, activity at $\mu$-opioid receptors could be central to maintaining or enhancing activity in spinal hyperalgesic circuits (see Mao, 1999, for review). In the absence of direct evidence, such a mechanism is speculative; it is offered simply to indicate that the behavioral evidence presented here is not inconsistent with the hypoalgesic function of opioid receptors. Further experimentation on the effects of specific opioid receptor subtype antagonists is needed to address this issue.

Finally, it is important to note that the pronociceptive function of opioid receptors shown here may not generalize to all forms of hyperalgesia. For instance, the conditioned hyperalgesia observed in the tail-flick test following intraoral infusion of a flavor previously paired with an injection of $\mathrm{LiCl}$ was reversed by opioid receptor antagonism (Wiertelak, Murray, Woronczuk, \& Koski, 1999). However, the hyperalgesia observed in this test when rats were exposed to a distinctive context previously paired with an injection of $\mathrm{LiCl}$ was naloxone insensitive (McNally et al., 1999). These discrepant findings not only argue strongly against interpretations emphasizing nonspecific effects of naloxone injection in reducing hyperalgesia, but they also highlight the complexity apparent in organization of endogenous pronociceptive circuits.

\section{References}

Bechara, A., \& Van der Kooy, D. (1985, April 11). Opposite motivational effects of endogenous opioids in the brain and periphery. Nature, 3/4, 533-534.

Berge, O.-G., Garcia-Cabrera, I., \& Hole, K. (1988). Response latencies in the tailflick test depend on tailskin temperature. Neuroscience Letters, $86,284-288$
Bolles, R. C., \& Fanselow, M. S. (1980), A penceptual-defensiverecuperative model of fear and pain. Behavioral Brain Sciences, 3 , 291-323.

Chen, L., \& Huang, L. Y. M. (1991). Sustained potentiation of NMDA receptor-mediated glutamate responses through activation of protein kinase $\mathrm{C}$ by $\mu$-opioids. Neuron, 7, 319-326.

Day, H. E. W., Curran, E. J., Watson, S. J., \& Akil, H. (1999), Distinct neurochemical populations in the rat central nucleus of the amygdala and bed nucleus of the stria terminalis: Evidence for their selective activation by interleukin-1. Journal of Comparative Neurology, 413, 113-128.

Harris, R. J. (1994). Analysis of variance primer. Itasca, Illinois: F. E. Peacock.

Hart, B. L. (1988). Biological basis of the behavior of sick animals. Neurascience and Biobehavioral Reviews, 12, 123-127.

Hays, W. L. (1972). Statistics for the social sciences. New York: Holt, Rinehart, \& Winston.

Hole, K., \& Tjolsen, A. (1993). The tailflick and formalin tests: Changes in tailskin temperature as a confounding factor. Pain, 53, 247-252.

Jensen, T. S., \& Yaksh, T. L. (1986). Comparison of antinociceptive action of morphine in the periaqueductal gray, medial and paramedial medulla in rat. Brain Research, 372, 301-312.

Kent, S., Bluthe, R. M., Kelley, K. W., \& Dantzer, R. (1992). Sickness behavior as a new target for drug development. Trends in Neurosciences, $13,24-28$

Lewis, J. W., Tordoff, M. G., Sherman, J. E., \& Liebeskind, J. C. (1982, August 6). Adrenal medullary enkephalin-peptides may mediate opioid stress analgesia. Science, 217, 557-559.

Lichtman, A. H., Smith, F. L., \& Martin, B. R. (1993). Evidence that the antinociceptive tailflick response is produced independently from changes in either tail-skin temperature or core temperature. Pain, 55 , 28.3-295.

Lieblich, I., \& Yirimiya, R. (1987). Naltrexone reversed a long term depressive effect of a toxic lithium injection on saccharin preference. Physiology and Behavior, 39, 547-550.

Madden, J. J., Whaley, W. L., \& Ketelsen, D. (1998). Opiate binding sites in the cellular immune system: Expression and regulation. Journal of Neuroimmunology, 83, 57-62.

Maier, S. F., \& Watkins, L. R. (1998). Cytokines for psychologists: Implications of bidirectional immune-to-brain communication for understanding behavior, mood, and cognition. Psychological Review, 105, 83-107.

Maier, S. F., Wiertelak, E. P., Martin, D., \& Watkins, L. R. (1993). Interleukin-1 mediates the behavioral hyperalgesia produced by lithium chloride and endotoxin. Brain Research, 623, 321-324.

Maier, S. F., Wiertelak, E. P., \& Watkins, L. R. (1992). Endogenous pain facilitory systems: Antianalgesia and hyperalgesia. American Pain Society Journal, 1, 191-218.

Mao, J. (1999). NMDA and opioid receptors: Their interactions in antinociception, tolerance and neuroplasticity. Brain Research Reviews, 30 , $289-304$.

Martin, G., Nie, Z., \& Siggins, G. R. (1997). Mu opioid receptors modulate NMDA receptor-mediated responses in nucleus accumbens neurons. Journal of Neuroscience, 17, 11-22.

McNally, G. P., \& Akil, H. (in press). Opioid peptides and their receptors: Overview and function in pain modulation. In D. Charney, J. Coyle, $\mathrm{K}$. Davis, \& C. Nemeroff (Eds.), Psychopharmacology: A fifth generation of progress. New York: Lippincott, Williams, \& Wilkins.

McNally, G. P., Gorrisen, M. C., Low, L.-F., \& Westbrook, R. F. (1999). Effects of contextual cues previously paired with footshock or illness on behavior and nociceptive sensitivity in the rat. Animal Learning \& Behavior, 27, 416-425.

McNally, G. P., \& Westbrook, R. F. (1998). Effects of systemic, intracerebral, or intrathecal administration of an $N$-methyl-D-aspartate receptor antagonist on associative morphine analgesic tolerance and hyperalgesia in rats. Behavioral Neuroscience, $112,971-983$. 
Mellon, R. D., \& Bayer, B. M. (1998). Evidence for central opiate receptors in the immunomodulatory effects of morphine: Review of potential mechanism(s) of action. Journal of Neuroimmunology, 83, 19-28.

Paxinos, G., \& Watson, C. (1986). The rat brain in stereotaxic coordinates. San Diego, CA: Academic Press.

Peterson, P. K., Molitor, T. W., \& Chao, C. C. (1998). The opioid-cytokinc connection. Journal of Neuroimmunology, 83, 63-69.

Pugh, C. R., Kuwagama, K., Fleshner, M., Watkins, L. R., Maier, S. F., \& Rudy, J. W. (1998). Selective effects of peripheral lipopolysaccharide administration on contextual and auditory-cue fear conditioning. Brain, Behavior, and Immunity, 12, 212-229.

Reisine, T. L., \& Pasternak, G. W. (1995). Opiate analgesics and antagonists. In J. G. Hardman and R. E. Limbird (Eds.), Goodman and Gilman's pharmacological basis of therapeutics (9th ed., pp. 521-527). New York: McGraw-Hill.

Ren, K., Randich, A., \& Gebhart, G. F. (1991). Spinal serotonergic and kappa opioid receptors mediate facilitation of the tailflick reflcx produced by vagal afferent stimulation. Pain, 45, 321-329.

Russell, J., Bass, P., Goldberg, L. I., Schuster, C. R., \& Merz, H. (1982). Antagonism of gut but not central effects of morphine with quatemary narcotic antagonists. European Joumal of Pharmacology, 78, 255-261.

Ruzicka, B. B., Thompson, R. C., Watson, S. J., \& Akil, H. (1996). Interleukin-1 $\beta$ regulation of $\mu$-opioid receptor mRNA in primary astrocyte enriched cultures. Joumal of Neurochemistry, 66, 425-428.

Schroeder, R. L., Weinger, M. B., Vakassian, L., \& Kuob, G. F. (1991). Methylnaloxonium diffuses out of the rat brain more slowly than naloxone after intracerebral injection. Neuroscience Letters, 121, 173-177.

Sharp, B. M., Roy, S., \& Bidlack, J. M. (1998). Evidence for opioid receptors on cells involved in host defense and the immune system. Journal of Neuroimmunology, 83, 45-56.

Shippenberg, T. S., Millan, M. J., Mucha, R. F., \& Her7, A. (1988). Involvement of beta-endorphin and mu-opioid receptors in mediating the aversive effect of lithium in the rat. European Journal of Pharmacology, $154,135-144$.

Storkson, R. V., Kjorsvik, A., Tjolsen, A., \& Hole, K. (1996). Lumbar catheterization of the spinal subarachnoid space in the rat. Journal of Neuroscience Methods, 65, 167-172.
Van der Kooy, D. (1986). Hyperalgesic function of peripheral opiate receptors. In D. D. Kelly (Ed.), Annals of the New York Academy of Sciences: Vol. 467. Stress-induced alagesia (pp. 152-168). New York: New York Academy of Sciences.

Watkins, L. R., Wiertelak, E. P., Furness, L. E., \& Maier, S. F. (1994). IIIness-induced hyperalgesia is mediated by spinal neuropeptides and excitatory amino-acids. Brain Research, 664, 17-24.

Watkins, L. R., Wiertelak, E. P., Goehler, L. E., Mooney-Heiberger, K., Martinez, J., Furness, L., Smith, K. P., \& Maier, S. F. (1994). Neuro. circuitry of illness-induced hyperalgesia. Brain Research, 639, 283-299.

Westbrook, R. F., Good, A. J., \& Kiernan, M. J. (1997). Microinjection of morphine into the nucleus accumbens impairs contextual learning in rats. Behavioral Neuroscience, 111, 996-1013.

Wiertelak, E. P., Furness, L. E., Watkins, L. R., \& Maier, S. F. (1994). Ilness-induced hyperalgesia is mediated by a spinal NMDA-nitric oxide cascade. Brain Research, 664, 9-16.

Wiertelak, E. P., Murray, A., Woronczuk, J., \& Koski, D. (1999). Illnessinduced and conditioned hyperalgesia neurochemistry: Intrathecal endogenous opiate specific receptor antagonist dose-response studies. Society for Neuroscience Abstracts, 25, 929.

Wiertelak, E. P., Roemer, B., Maier, S. F., \& Watkins, L. R. (1997). Comparison of the effects of nucleus tractus solitarus and ventral medial medulla lesions on illness-induced and subcutaneous formalin-induced hyperalgesias. Brain Research, 748, 143-150.

Wiertelak, E. P., Smith, K. P., Furness, L., Mooney-Heiberger, K., Mayr, T., Maier, S. F., \& Watkins, L. R. (1994). Acute and conditioned hyperalgesic responses to illness. Pain, 56, 227-234.

Yirimiya, R., Rosen, H., Donchin, O., \& Ovadia, H. (1994). Behavioral effects of lipopolysaccharide in rats: Involvement of endogenous opioids. Brain Research, 648, 80-86.

Received June 11, 1999 Revision received May 15, 2000 Accepted May 17, 2000 